\title{
The relationship between particle strength and particle breakage in loaded gravels
}

\author{
Stephen Fityus ${ }^{1 *}$ and John Simmons ${ }^{1,2}$ \\ ${ }^{1}$ The School of Engineering, University of Newcastle, University Drive, Callaghan, Australia, 2308. \\ ${ }^{2}$ Sherwood Geotechnical and Research Services, Peregian Beach QLD, Australia 4573
}

\begin{abstract}
The particle breakage behaviour of coarse grains during shearing of a gravelly granular assemblage changes in accordance with the magnitude of the confining stress acting on the assemblage. The transition from particle rearrangement and sliding to particle breakage is studied for two gravelly materials subjected to a wide range of compressive and shear stresses (10kPa to $3.5 \mathrm{MPa})$. The tested materials are a gravel fraction derived from crushed sedimentary sandstones and shales, and a gravel derived from a crushed rhyodacitic volcanic. At low confining stresses, breakage due to compression and shear are both small, with only some fine fragments produced. Confining stress increase results in a stage being reached where particle damage starts to increase greatly, under both compressive and shearing loads. The results indicate that, as stresses become very large, the particle breakage due to compression continues to increase, but the breakage due to shearing under the same vertical stress actually decreases. This is attributed to the attainment of a fabric which, through extreme damage during compression, allows subsequent shearing with reduced additional particle damage.
\end{abstract}

\section{Introduction}

The shear strength of granular materials with crushable particles is determined by the complex contribution of several phenomena including particle rubbing, sliding and rolling, as well as particle breakage, which may involve comminution of thin corners/edges or complete particle failure [1]. Generally, rubbing, sliding and rolling dominate under lower stresses, whereas breakage becomes more prevalent as applied stresses increase and dilation is suppressed [2]. As a result, it is believed that the shear strength envelope is non-linear $[3,4]$.

However, the relationship between the particle strength and the stress conditions which would cause the particles to become damaged (as opposed to simply rearranged) during shearing are poorly understood.

In this study, two crushed rock materials, of different strength, were subjected to direct shear testing over an extreme range of stresses, and the resulting particle breakage was inferred from the amount of fines produced. From this, insights are gained for the relationship between particle strength, confining stress and particle damage.

\section{Methods}

The samples tested in this research were a relatively weak sedimentary rock, dominated by siltstone, derived from the waste rock from a coal mine in the Permian Sydney Basin of Australia, and a rhyodacite ignimbrite taken from a quarry in the Carboniferous volcanics of the New England Fold Belt. Unconfined compressive strength (UCS) measurements of samples of the sedimentary rocks in the sampled geological sequence ranged from 25 to $40 \mathrm{MPa}$ with a mean value of around $35 \mathrm{MPa}$. UCS tests on samples from the rhyodacite quarry ranged from 150 to $177 \mathrm{MPa}$ with a mean value of around $170 \mathrm{MPa}$.

For the purposes of this study, damage was characterised by the production of fines, where fines were defined as any particles passing the $4.75 \mathrm{~mm}$ sieve. So as to avoid issues with possible size effects [5][6], each sample was prepared to have the same range of initial particle sizes, ranging between 4.75 and $19.6 \mathrm{~mm}$.

Tests were performed using a $300 \times 300 \mathrm{~mm}$ Prolab Direct Shear Machine (DSM) with a 1MPa capacity (Fig 1a). Tests were carried out with normal stresses ranging from $9 \mathrm{kPa}$ to $12 \mathrm{MPa}$. So as to achieve stresses greater than $1 \mathrm{MPa}$, concrete and steel inserts with a $167 \mathrm{~mm}$ circular sample space were manufactured, that could be inserted into the $300 \mathrm{~mm}$ shear boxes, reducing the area of the sample by about $75 \%$ (Fig 1b). For stresses less than $100 \mathrm{kPa}$, the mass of the shear box and insert became significant, and hydraulic control of the DSM was unable to apply and maintain the stress to sufficient accuracy. So, in the case of the 9 and $48 \mathrm{kPa}$ tests, a special lightweight top box was fabricated and the normal load was applied using deadweights (Fig 1c). For the stress of $12 \mathrm{MPa}$ only, an additional $104 \mathrm{~mm}$ diameter insert was used to further reduce the sample area.

Samples were carefully prepared by sieving the required fractions from bulk samples. The basic fractions

* Corresponding author: stephen.fityus@,newcastle.edu.au 
of each material are shown in Fig 2. A fraction mixture with roughly $1 / 4$ of each size was selected. After several bench trials, a target mass was determined to allow samples to be prepared to the same consistent, loose initial density for each test.

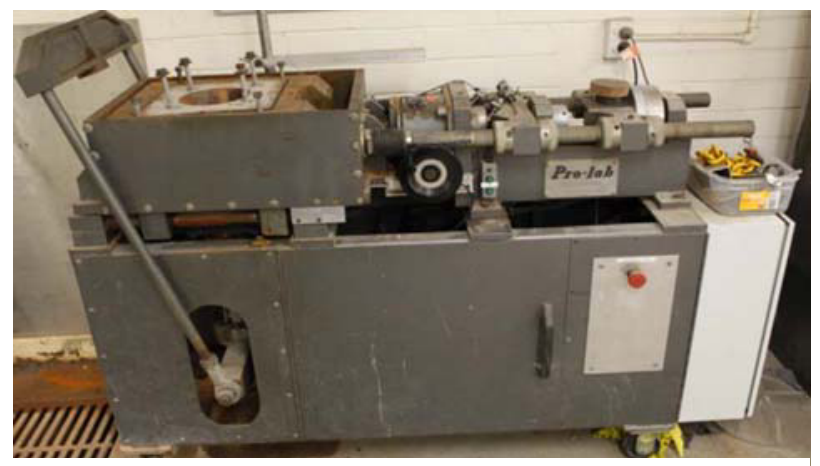

a) Prolab direct shear machine, with inserts installed

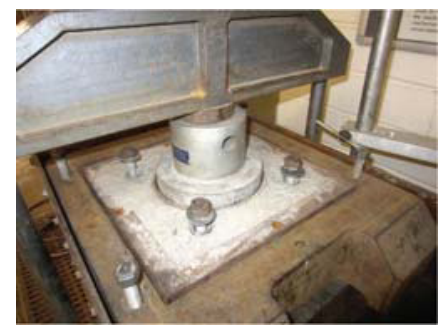

b) sample insert under hydraulic load

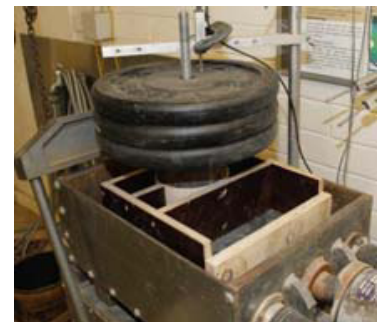

c) lightweight top box and loading weights
Fig. 1. Features of the testing arrangement.

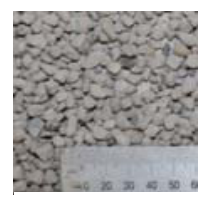

$21.3 \%$ $4.75-6.7 \mathrm{~mm}$

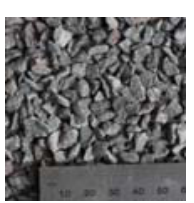

$21.6 \%$ $4.75-6.7 \mathrm{~mm}$

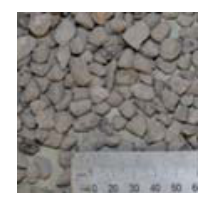

Siltstone $23.4 \%$ $6.7-9.5 \mathrm{~mm}$

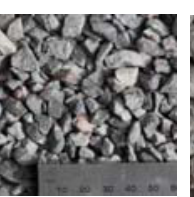

Rhyodacit

$$
\begin{array}{cc}
23.5 \% & 23.5 \% \\
6.7-9.5 \mathrm{~mm} & 9.5-13.2 \mathrm{~mm}
\end{array}
$$

Fig. 2. Basic fractions used to create the initial samples.

Acknowledging that significant particle breakage may occur in the application of the normal compressive stress, even before the sample is sheared, particle breakage during shear was estimated as follows:

1. Prepare a new sample, apply compression, determine fines.

2. Prepare a new sample, apply compression, shear, determine fines.

3. Estimate fines due to shear as the difference between samples tested by compression and shear (2.), and compression only (1.).
Determination of fines after compression and/or shearing involved careful recovery of all the tested material and a sieve analysis. After testing under 3.5 and $12 \mathrm{MPa}$, the compression of the siltstone in particular, was so substantial that the recovered sample was effectively a monolith. Before it could be sieved, it had to be broken up. This was achieved very carefully by gently teasing out crushed and recompacted material that had clearly been reconstituted by the test process, whilst not breaking down primary particles that had not been damaged.

\section{Results}

Figure 3 shows examples of samples of both tested materials, after testing by compression and shearing, under low and very high stress. The intense compression of the siltstone under $12 \mathrm{MPa}$ is clearly evident.
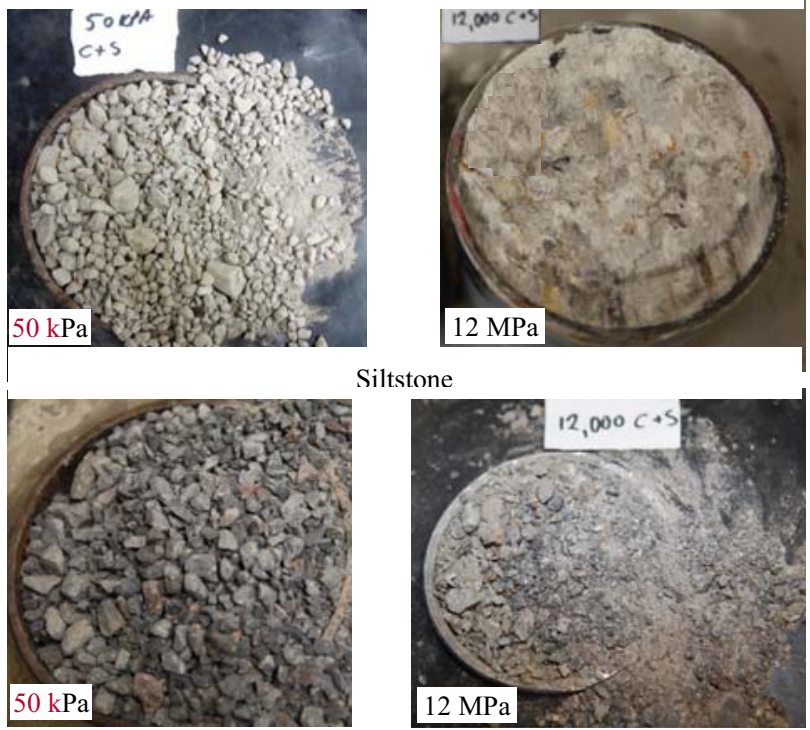

Rhyodacite

Fig. 3. Characteristics of samples after testing.

Fig 4 shows the particle crushing results for both material types, with a number of outcomes evident:

- The weaker siltstone material produces more fines than the rhyodacite for a given stress, as expected.

- A higher proportion of fines was produced during confined compression than during shear.

- The percentage fines produced by confined compression is small under very low stress $(9 \mathrm{kPa})$ and increases slowly with increasing stress, until reaching some "threshold" stress, whereafter the percentage fines produced increases rapidly, but at a steady rate with increasing log stress.

- The percentage fines produced during shear is small under very low stress $(9 \mathrm{kPa})$ and increases steadily with increasing log stress, until reaching some "critical" stress. Beyond the critical stress, the percentage fines produced decreases with increasing stress, despite the fines produced during compression increasing logarithmically. 


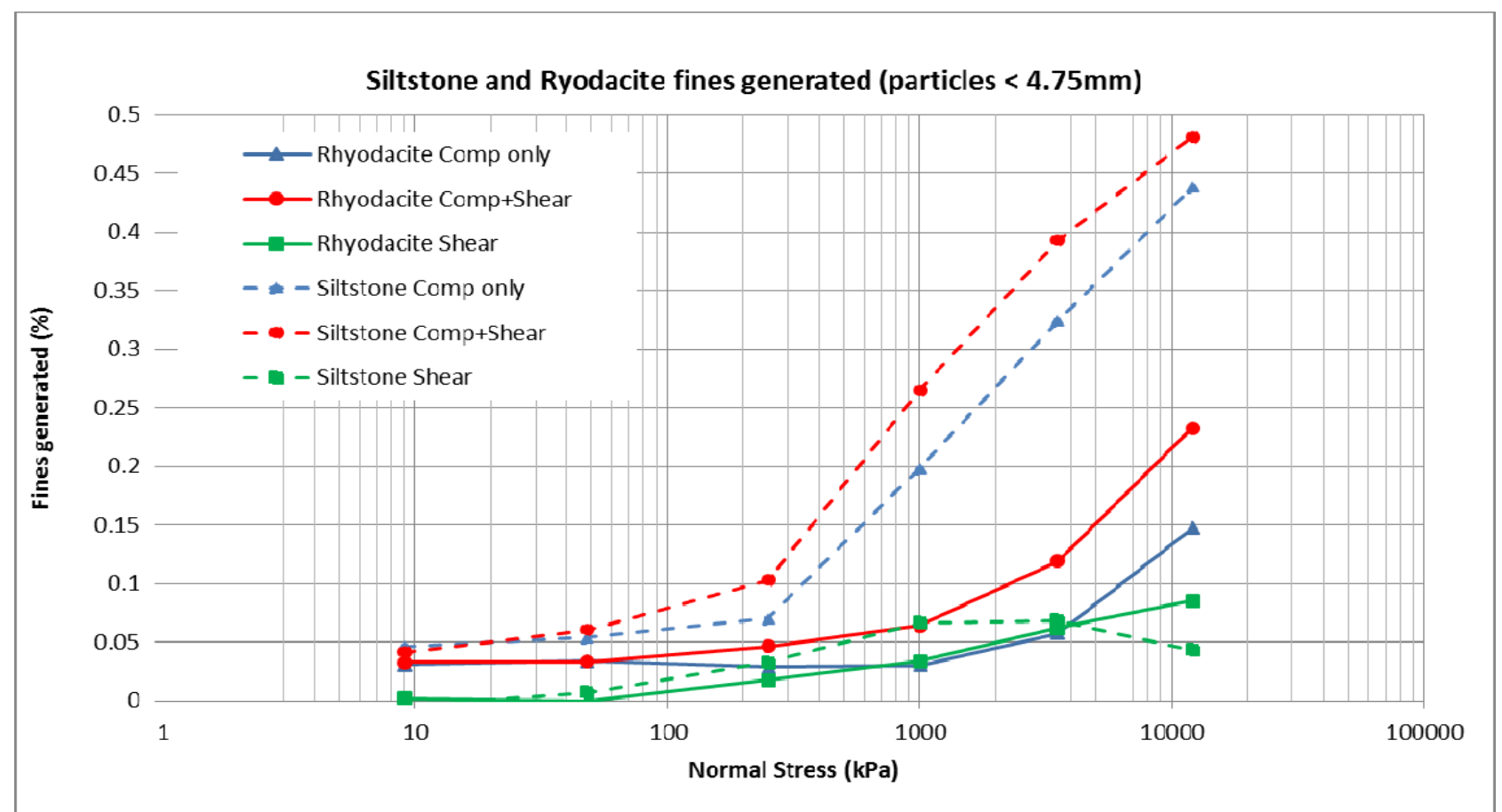

Fig. 4. Percentage fines generated after compression, compression and shear and shearing for the siltstone and rhyodacite samples.

The normal displacement vs shear displacement responses for each material are shown in Fig 5. It is evident that dilation ceases in the weaker siltstone material between normal stresses of 48 and $250 \mathrm{kPa}$, but it persists in the stronger rhyodacite material up to stresses of between 1 and $3.5 \mathrm{MPa}$.
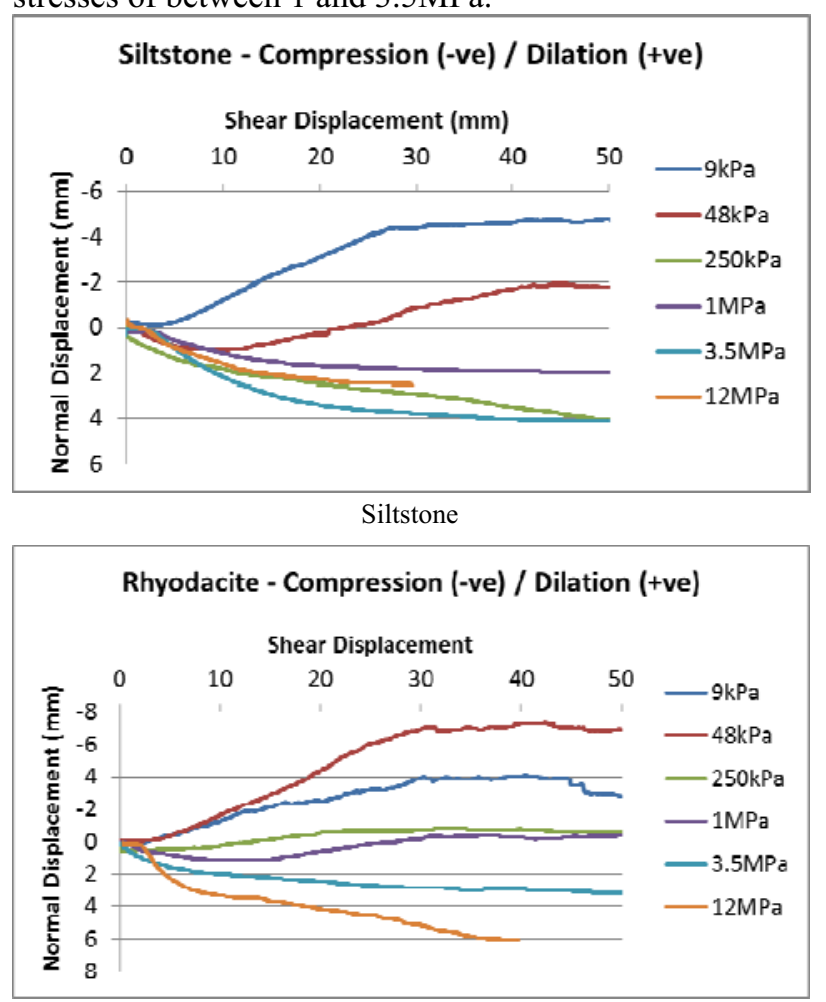

Rhyodacite

Fig. 5. Normal displacement vs shear displacement curves.
The peak shear stress obtained during each tests is plotted against normal stress in Fig 6. It is apparent that the shear stresses are proportionally larger at lower stresses, and that this is more so the case for the stronger rhyodacite material.

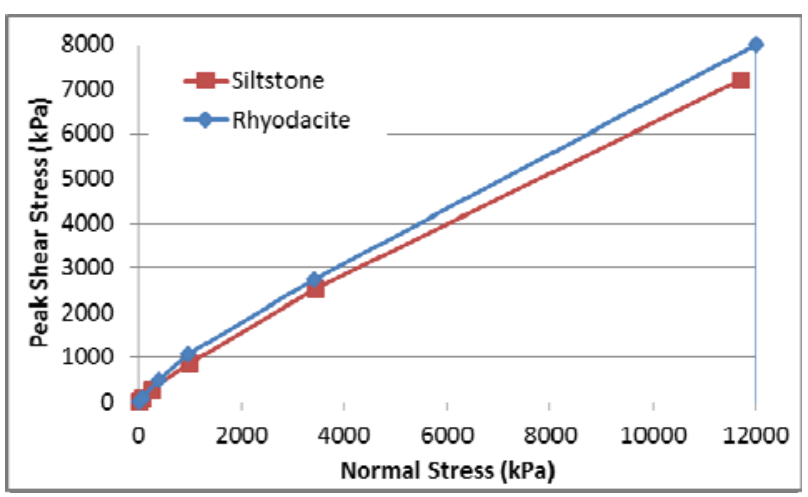

Fig. 6. Peak shear stress vs normal stress curves.

\section{Discussion and Analysis}

The "threshold" stresses for each material can be estimated by fitting two tangent lines to the obvious linear segments of the compression and compression + shear curves in Figure 4, taking their point of intersection as the threshold stress. For the siltstone material, the threshold stress is close to $250 \mathrm{kPa}$ for both compression and compression + shear, whilst for the rhyodacite it is around $2.3 \mathrm{MPa}$ for compression only and $1.3 \mathrm{MPa}$ for compression + shear. These values represent $0.7,0.8$ and $1.4 \%$ of the UCS of the corresponding 
parent rock materials, respectively. The values of 0.7 and 0.8 for the threshold stress ratio under compression are consistent, and although they fall far short of being definitive values, they give some insight of the relationship between particle material strength and the role of particle breakage in highly stressed rockfill materials.

The threshold stress is a prominent feature of the results involving sample compression, but it is not reflected in the derived results for the fines produced during shearing only. On this basis it is interpreted as representing that stress under which the response to compression transitions from particle rearrangement with chipping and crushing of particle points and edges, to full particle breakage, with crushing and splitting. It is also evident that the transition between particle breakage modes is gradual, with the threshold stress being an idealisation of a more transitional phenomenon.

The phenomenon of a "critical stress", where the percentage of fines produced during shearing reaches a peak value, was not anticipated, but is readily explained. In order to achieve a shearing mechanism under high stresses, particles must be damaged, as they cannot be rearranged after being densely compacted during heavy compression. However, with increasing vertical stress, the amount of particle damage during compression (application of the normal stress) becomes so great that it reaches an extent where a shearing mechanism can be achieved without having to break an increasing number of particles.

The critical stress was only clearly reached for the siltstone material for the stresses applied, and its value is somewhere between $1 \mathrm{MPa}$ and $3.5 \mathrm{MPa}$; probably around $2 \mathrm{MPa}$. This corresponds to around $6 \%$ of the siltstone UCS. The data in Figure 4 suggests that the critical stress for the rhyodacite is in excess of $12 \mathrm{MPa}$ and that the percentage fines produced during shear at the critical stress will be greater for the stronger rhyodacite than for the weaker siltstone.

The curvature in the relationship between peak shear strength and normal stress (Fig 3) is consistent with that observed by many previous authors [3],[4], and its interpretation is consistent with the generally accepted view that the shear strength under low stress is higher due to the phenomenon of dilation. The greater curvature in the rhyodacite results is entirely consistent with the persistence of dilation in the rhyodacite to significantly higher stresses (Fig 5). The results are consistent with [7] who found for crushed rocks, the shear strength parameters decreased consistently up to normal stresses of $1 \mathrm{MPa}$ for strong materials.

In evaluating these results, it should be appreciated that the measure of particle breakage adopted here is a relatively simple one: creation of fragments smaller than $4.75 \mathrm{~mm}$. The full results (not presented here) indicate that there was corresponding degradation in the larger particles of all sizes, with the proportion of the largest particles decreasing steadily with increasing log normal stress. Additional insights can be gained from a consideration of the full set of results, though space does not permit this here.

\section{Conclusions}

As expected, the particle breakage of crushed rock materials increases with increasing applied stress, in a manner which reflects the strength of the parent rock material. Under compressive loading, a threshold normal stress is recognised where the rate of particle breakage suddenly increases rapidly, corresponding to a transition from particle sliding and chipping, to full particle crushing and splitting. The threshold stress appears to correspond to around $0.7 \%$ of the material UCS.

With increasing normal stress, the particle breakage which occurs due to application of the normal stress continues to increase steadily, whereas the breakage due to subsequent shearing seems to reach a peak amount (at some critical stress) before actually decreasing for even higher stresses. This behaviour is attributed to the role of the compressive stress in achieving so much breakage under high stresses, that a shearing mechanism can then be achieved which requires less additional breakage than would be required under lower stresses. For the weaker siltstone material, the critical stress was found to be around $6 \%$ of the UCS.

The authors would like to acknowledge the excellent work of Mr Robert Dun in obtaining the experimental results, and the funding support of Australian Coal Research Limited.

\section{References}

1. Ovalle, C., Dano, C., Hicher, P.-Y., Cisternas, M. (2015). Experimental framework for evaluating the mechanical behavior of dry and wet crushable granular materials based on the particle breakage ratio. Canadian Geotechnical Journal 52, No. 5, 587598.

2. Marsal, R. (1973). Mechanical properties of rockfill dams in Embankment dam engineering: Casagrande Volume., eds. Hirschfeld, R.C., Poulos, S.J. Wiley, New York, pp 109-200.

3. Leps, T.M. (1970). Review of shearing strength of Rockfill. J. Soil Mech. Found. Div. ASCE 96, No. 4, 246 1159-1170

4. Indraratna, B., Wijewardena, L., Balasubramaniam, A. (1993). Large-scale triaxial testing of greywacke rockfill. Géotechnique 43, No. 1, 539-543

5. Ovalle, C., Dano, C., Hicher, P.-Y. (2013). Experimental data highlighting the role of surface fracture energy in quasi-static confined comminution. International Journal of Fracture, Vol. 182 , No. 1, 123-130.

6. Weibull, W. (1939). A statistical theory of the strength of materials. Proceedings of Royal Swedish Inst. Eng. Res. 151

7. Anagnosti, P. and Popovic, M. (1982) Evaluation of shear strength for coarse-grained granular materials. Fourteenth Congress on Large Dams, Rio de Janeiro, ICOLD. Vol. Q55 pp. 753-767. 